
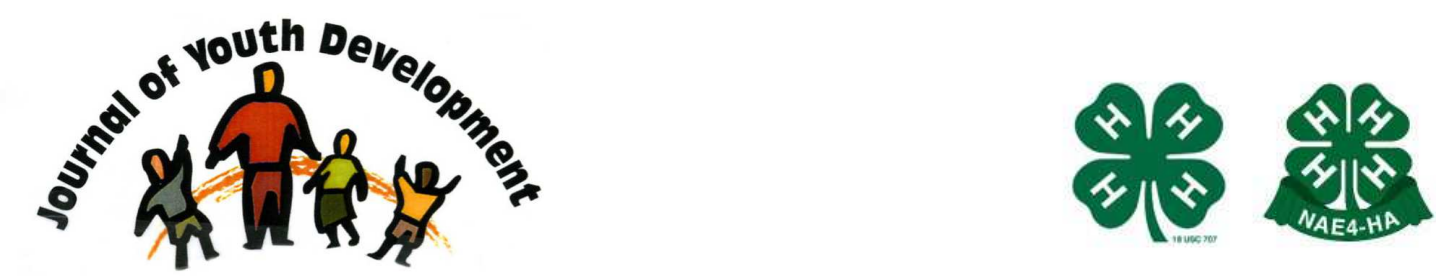

Bridging Research \& Practice

\title{
West Virginia's Response to the Rotten Truth about Oral Health
}

\author{
Brent Clark \\ West Virginia University Extension Service \\ Clarksburg, WV \\ Brent.Clark@mail.wvu.edu \\ Elaine Bowen \\ West Virginia University Extension Service \\ Chad Higgins \\ West Virginia University Extension Service \\ Zona Hutson \\ West Virginia University Extension Service \\ Gina Sharps \\ West Virginia University Health Sciences Center \\ Tracy Waugh \\ West Virginia University Extension Service
}




\title{
JOURNAL OF YOUTH DEVELOPMENT \\ bridging research and practice

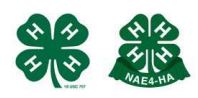

Volume 3, Number 3, Winter 2008

Article 080303PA003

\section{West Virginia's Response to the Rotten Truth about Oral Health}

Brent Clark, Elaine Bowen, Chad Higgins, Zona Hutson, Tracy Waugh

West Virginia University Extension Service

Gina Sharps

West Virginia University Health Sciences Center

\begin{abstract}
West Virginia University Extension Service has taken steps to increase the awareness and practices of good oral health. Significant barriers exist for optimal dental health and preventive care for youth in West Virginia. The 4-H Health Initiative strengthens community 4-H clubs through joint commitment to improve the Health " $\mathrm{H}$," club reliance on youth leadership, responsiveness to youth voices, and involvement of community health resources. These efforts bring oral health education and services to school-age youth. Evaluation data suggest that the model may impact oral health behaviors.
\end{abstract}

\section{Introduction}

Good oral health is essential to overall wellness. According to the United States Surgeon General's Report on Oral Health (2003), tooth decay is the single most common chronic childhood disease. Children miss more than 51 million school hours each year due to dentalrelated illness. This report also states that dental decay and gum disease are communicable infectious diseases linked to low birth weight, cardiovascular conditions, cancer, diabetes, poor nutrition, speech impairments, and psychosocial problems. In 2006, the West Virginia Department of Health and Human Resources concluded that eighty-four percent of West Virginia youth have cavities by high school graduation. Despite the rotten truth concerning dental disease, it is preventable when healthy habits begin early in life.

Barriers may prevent youth from receiving appropriate dental education, screening, and care. According to the U.S. General Accounting Office (2000), such barriers include a limited number 
of dental health practitioners, lack of transportation, cultural beliefs or misconceptions, low educational levels, and financial constraints.

Ensuring good oral health requires both community responsibility and personal actions. The West Virginia 4-H Health Initiative provides necessary elements to address this important issue. Through a new 4-H health officer program, West Virginia University Extension Service (WVUES) aims to improve awareness of oral health and reduce disparities among youths. An innovative partnership with WVUES, the West Virginia University School of Dentistry, and the West Virginia Office of Maternal, Child and Family Health/Oral Health Program engages youth and parents to actively learn and modify oral health attitudes and practices.

\section{Program Design}

Consistent with the national 4-H healthy lifestyles mission mandate, the West Virginia 4-H youth development program created a youth health officer position. Similar to other elected 4-H club officers, these youths are selected by their peers. They are trained and responsible for leading health activities during club meetings and other 4-H events. The pilot program focused on dental health content. It was pilot tested in four counties in 2006. Project goals were:

- To develop meaningful youth leadership roles within 4-H and their communities.

- To create focused, culturally appropriate and sequential messages and hands-on activities delivered at nine monthly club meetings.

- To build internal and external youth assets through planning and delivery of key oral health messages.

- To encourage communications between youth and parents regarding healthy dental habits.

- To increase organizational partnerships and resources.

\section{Target Audience}

The 4-H health officer program was designed for traditional, community-based 4-H clubs managed by adult volunteer leaders. Typically, club members range in age from 8 to 21 . The majority of 4-H members are ages 10 to 14 . Clubs meet monthly for business, education, and recreation. Meetings may be held in a variety of settings - homes, community centers, schools, and places of worship. Because of the nature of this learning environment, health education experiences were developed to be dramatic, short, interesting, and factual.

\section{Program Delivery}

A multidisciplinary team of Extension professionals and partners formulated the initial concept and guided the pilot program. The following steps were conducted:

- Formulated the initial plan using the experiential learning model, the Targeting Life Skills Model (2004), and the Search Institute's Developmental Assets framework (2004).

- Defined the youth health officer as a primary peer conduit of health information.

- Created the health officer curriculum with a focus on dental health.

- Involved youth and adult volunteers in curriculum preview and critique. 
- Recruited members as health officers for community-based 4-H clubs.

- Trained health officers with the aid of a community dental health professional.

- Examined parent perceptions via surveys.

- Distributed materials:

West Virginia 4-H Club Health Activity Guide: Dental for officers

West Virginia 4-H Club Health Planner: Dental for club youth

Toothbrushes, toothpaste, dental floss, and mouth guards for all youths

Officer record forms to document meeting outcomes

A dental resource kit for health officers containing DVDs, visuals, and manipulatives

- In 2005 , curriculum pieces were piloted with 1,200 youths in four counties. The curriculum was revised and distributed statewide in the fall of 2006, reaching 18,000 youths.

The activity guide is an in-depth curriculum piece to assist youth health officers in leading activities focused on improving specific dental habits. The guide has a health officer job description, training guide, program introduction, dental facts, club activities for nine monthly topics, and resource list. Each club activity encourages youths to set goals to achieve a monthly challenge. For example, during April, youths try to "replace sugar-added drinks with water and low-fat milk." To reinforce the importance of personal daily dental behaviors, each 4-H youth received a health planner. This companion piece enabled youths to set goals and monitor progress on monthly challenges. To support positive family involvement, the planner was designed to encourage parent-child interaction through puzzles, trivia, and tips. 4-H Family Handouts on dental topics reinforce monthly challenges and urge parent-child discussion.

\section{Methodology and Findings}

Selected aspects of the pilot program were evaluated using a 4-H Parent Survey. These characteristics were determined appropriate by the expert panel consisting of youth development and dental professionals. The survey and protocol were approved by WVUES according to Institutional Review Board policies. The one-page, 13-item survey was created and distributed to parents of 4- $\mathrm{H}$ youth involved in the health initiative. A total of 245 completed surveys were analyzed (a $24 \%$ return rate). The youths were 62.1 percent female and 37.9 percent male. The youth mean age was 12.76 years.

Parents reported $32 \%$ of children used the $4-\mathrm{H}$ Health Planner as a planner and $36 \%$ used it as a calendar. Results suggest the planner may be a valuable tool to prompt parent-child discussions and behaviors. A correlational procedure examined possible relationships between the planner usage and desired program outcomes. Table 1 displays relationships between the increase of planner usage and parent-child discussions. 
Table 1

Correlations between Planner Usage and Parent-Child Discussions $\mathrm{N}=245$

\begin{tabular}{|l|c|l|}
\hline Selected Variable & $r$ & Interpretation \\
\hline Discussions of dental brushing increased & .53 & substantial \\
\hline Discussions of consuming healthier foods increased & .54 & substantial \\
\hline Discussions of tracking dental habits increased & .66 & substantial \\
\hline Selected Variable & $r$ & Interpretation \\
\hline Discussions of tobacco usage increased & .7 & very high \\
\hline Discussions of consuming healthier foods increased & .71 & very high \\
\hline Discussions of tracking dental habits increased & .65 & substantial \\
\hline Discussions of dental visits increased & .77 & very high \\
\hline Discussions about flossing increased & .75 & very high \\
\hline Selected Variable & $r$ & Interpretation \\
\hline Discussions of tobacco usage increased & .71 & very high \\
\hline Discussions of using a fluoride mouthwash increased & .63 & substantial \\
\hline Discussions of consuming healthier foods increased & .71 & very high \\
\hline Discussions of tracking dental habits increased & .64 & substantial \\
\hline Discussions of dental visits increased & .8 & very high \\
\hline
\end{tabular}

Notes: $p<.001$

Interpretations of Davis's (1971) Descriptors: .01-.09 (negligible); .10-.29 (low); .30-.49 (moderate); .50-.69 (substantial); .70-.99 (very high). Correlations for non-significant correlations were determined to have negligible effect size.

Another crucial educational component of the program was to alter behaviors associated with potentially detrimental dental habits. Structured educational challenges within the curriculum exposed youth to healthier habits and promoted dental hygiene. According to parent survey results, the most prevalent behavior changes parents observed were drinking water more often, getting new toothbrushes, and eating more fruits and vegetables. See Table 2.

Table 2

Frequencies of Parent Observations of their Child's Dental Habits N=245

\begin{tabular}{|l|r|r|r|r|}
\hline \multicolumn{1}{|c|}{ Changes Observed by Parent } & $\begin{array}{c}\text { Percent } \\
\text { Less Often }\end{array}$ & $\begin{array}{c}\text { Percent } \\
\text { No Change }\end{array}$ & $\begin{array}{c}\text { Percent } \\
\text { More Often }\end{array}$ & $\begin{array}{c}\text { Percent } \\
\text { Not Sure }\end{array}$ \\
\hline Brushing teeth & .5 & 67.0 & 29.6 & 2.9 \\
\hline Flossing teeth & 1.0 & 67.1 & 27.5 & 4.3 \\
\hline Using mouthwash & 1.0 & 62.9 & 32.7 & 3.4 \\
\hline Using fluoride rinse & 2.5 & 72.0 & 18.5 & 7.0 \\
\hline Drinking water & .5 & 49.0 & 47.5 & 3.0 \\
\hline Drinking soda pop & 26.8 & 61.6 & 8.1 & 3.5 \\
\hline Getting a new toothbrush & 1.0 & 55.4 & 41.2 & 2.5 \\
\hline Eating sugary snacks & 20.8 & 65.6 & 9.3 & 4.4 \\
\hline Eating fruits and vegetables & 2.2 & 59.2 & 33.9 & 4.3 \\
\hline $\begin{array}{l}\text { Wearing a mouth guard when playing } \\
\text { sports }\end{array}$ & 3.0 & 76.5 & 11.4 & 9.0 \\
\hline
\end{tabular}


To date, findings of this study include:

1. The program had a positive impact on targeted oral health behaviors (e.g., brushing, flossing, fluoride rinse, mouthwash, mouth guard, and toothbrush replacement).

2. Complimentary health habits were positively affected (e.g., increased consumption of fruits and vegetables, water, and decreased consumption of soda and sugary snacks).

3. Planner usage helped youth form and establish improved oral health habits.

4. The program increased family discussion concerning dental-related habits.

\section{Resources and Funding}

This initiative could be replicated in any state or county program involving school-age youth. Currently, West Virginia 4-H community clubs and selected after-school programs and school classrooms are involved in the program. In addition, 4-H Family Handouts are used in adult health programs. Curriculum resources are adaptable for various situations. To ensure success, the following components are essential:

1. enthusiasm for promoting health by youth professionals and volunteers;

2. partnerships with health professionals and organizations;

3. a volunteer training system; and

4. funds to purchase or develop curriculum materials.

From the West Virginia 4-H program experience, it is clear that schools of dentistry, community dental professionals, state health departments, and private foundations are eager to contribute resources to worthy youth leadership and health projects. For example, partners contributed inkind staff time for program development and outreach education, health incentives (toothbrushes, floss, mouth guards, posters), and monies to cover curriculum printing, volunteer training, and teaching tools.

\section{Program Impact}

Although the initiative is in a formative stage, there are many signs of success. The program brings health education directly to school-age youth through the strong, sustained community network of 4-H clubs, youth, parents, volunteers, faculty, and experts. With focused and culturally relevant health messages and hands-on activities, the curriculum engages $4-\mathrm{H}$ members and families.

The addition of the youth 4-H Health Officer provides significant leadership opportunities. Trained officers learn and practice leadership and health while involving club members in activities such as roll call, experiments, games, and personal challenges. 4-H'ers using the planner try monthly health challenges and track health-promoting behaviors. In addition, monthly family handouts foster parent-child communication, prompting improved daily dental habits.

The emerging partnerships, commitments, and resources were essential in developing the successful 4-H Health Initiative. 4-H demonstrated its potential to make an impact on the oral 
health status of youth. In fact, in 2005 the national advocacy group Oral Health America awarded West Virginia "extra credit" status for increasing collaborations (2005). According to its report, "Partnerships in West Virginia are leading to creative solutions to access and utilization problems in this rural state...This information will help the state improve self-care and to increase utilization of dental services," (Oral Health America, page 11).

\section{Conclusions}

This promising model is an effective way to involve youth leaders in providing peer health education. It appears to bring synergy to partner organizations whose shared mission is to address such critical problems as oral health and to improve youth and family well-being.

\section{References}

Iowa State University. (2004). Targeting life skills training model. Retrieved from: www.extension.iastate.edu/4H/lifeskills/previewwheel.html

Oral Health America. (2005). A for effort: Making the grade in oral health. Retrieved from: www.oralhealthamerica.org

Search Institute. (2004). Developmental assets. Retrieved from: www.search-institute.org

U.S. Department of Health and Human Services. (2003). A national call to action to promote oral health. (NIH Publication No. 03-5303). Rockville, MD: U.S. Department of Health and Human Services.

U.S. General Accounting Office. (2000). Oral health: Factors contributing to low use of dental services by low-income populations. (GAO Publication No. GAO/HEHS-00-149). Washington, DC: U.S. General Accounting Office, Public Health Service, Centers for Disease Control and Prevention, National Institutes of Health, National Institute of Dental and Craniofacial Research.

West Virginia Department of Health and Human Resources. (2006). West Virginia Healthy People 2010, section 21, oral health. Retrieved from: www.wvdhhr.org/bph/hp2010/ .

(c) Copyright of Journal of Youth Development $\sim$ Bridging Research and Practice. Content may not be copied or emailed to multiple sites or posted to a listserv without copyright holder's express written permission. Contact Editor at: patricia.dawson@oregonstate.edu for details. However, users may print, download or email articles for individual use.

ISSN 2325-4009 (Print); ISSN 2325-4017 (Online) 